\title{
Impact of Different Definitions of Airflow Limitation on the Prevalence of Chronic Obstructive Pulmonary Disease in the General Population
}

\author{
Sven Gläser ${ }^{a}$ Christoph Schäper ${ }^{a} \quad$ Anne Obst $^{a} \quad$ Till Ittermann $^{b}$ Henry Völzke ${ }^{b}$

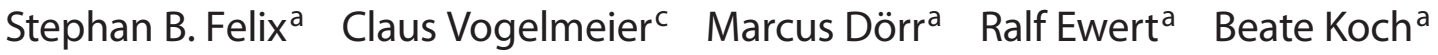 \\ ${ }^{a}$ Department of Internal Medicine B - Cardiology, Intensive Care, Pulmonary Medicine and Infectious Diseases, \\ University of Greifswald, and ${ }^{b}$ Institute for Community Medicine, SHIP/Clinical-Epidemiological Research, \\ Ernst Moritz Arndt University, Greifswald, and 'Department of Pulmonary Medicine, University of Marburg, \\ Marburg, Germany
}

\section{Key Words}

Airflow limitation - Chronic obstructive pulmonary disease • Prevalence of pulmonary diseases $\cdot$ Smoking

\begin{abstract}
Background: Recent surveys report a surprisingly high prevalence of chronic obstructive pulmonary disease (COPD) worldwide. However, there is evidence that the application of a fixed ratio of forced expiratory volume in $1 \mathrm{~s}\left(\mathrm{FEV}_{1}\right)$ to forced vital capacity (FVC) may result in a relevant misclassification of airflow limitation. Objectives: The definition of airflow limitation does have a significant impact on its prevalence. Methods: Individual values of lung volumes were assessed in comparison to a reference population by applying either a fixed ratio below 0.7 or the fifth percentile of $\mathrm{FEV}_{1}$ in relation to FVC. Based on a large-scale population-based survey, reference equations for lung volumes were derived by quantile regression analysis based on 1,809 subjects aged 25-85 years. Both functional definitions were applied to calculate the prevalence of airflow limitation. Results: The prevalence of airflow limitation was significantly higher when applying the fifth percentile compared to the fixed ratio of 0.7 for all age groups and both sexes (all 6.7 vs. $1.9 \%$; women 6.7 vs. $1.3 \%$; men 6.6 vs. $2.6 \%$ ). Almost $26 \%$ of the
\end{abstract}

subjects with airflow limitation complained of dyspnea, whereas COPD had not been previously diagnosed by a physician in $87 \%$. Conclusion: The definition of airflow limitation has a major impact on the observed prevalence rates.

Copyright $\odot 2010$ S. Karger AG, Basel

\section{Introduction}

Chronic obstructive pulmonary disease (COPD) is one of the most important diseases worldwide [1]. According to the WHO Global Burden of Disease Project, COPD ranked sixth among all causes of death in 1990 and is expected to rank third in $2020[2,3]$. The Burden of Obstructive Lung Disease Study (BOLD) recently reported a prevalence ranging between 11.1\% (Guangzhou, China) and 26.1\% (Salzburg, Austria). Among others, biomass, dust and solid-fuel exposure are additional relevant risk factors for COPD [2]. However, a consistent finding throughout the world is that airflow limitation and COPD are almost always associated with smoking (males: 92.6-96.5\% and females: 91.4-97.1\%) [1].

In addition to demographic differences in the investigated populations, the prevalence of airflow limitation is strongly dependent on the definition the diagnosis is

\section{KARGER}

Fax +41613061234 E-Mail karger@karger.ch www.karger.com
(C) 2010 S. Karger AG, Basel

0025-7931/10/0804-0292\$26.00/0

Accessible online at:

www.karger.com/res
Sven Gläser, MD, Medical Faculty of the Ernst Moritz Arndt University

Department of Internal Medicine B - Cardiology

Intensive Care, Pulmonary Medicine and Infectious Diseases

Friedrich-Loeffler-Str. 23, DE-17475 Greifswald (Germany)

Tel. +49 3834862 2401, Fax +49 3834862 2422, E-Mail glaeser.sven@ gmail.com 


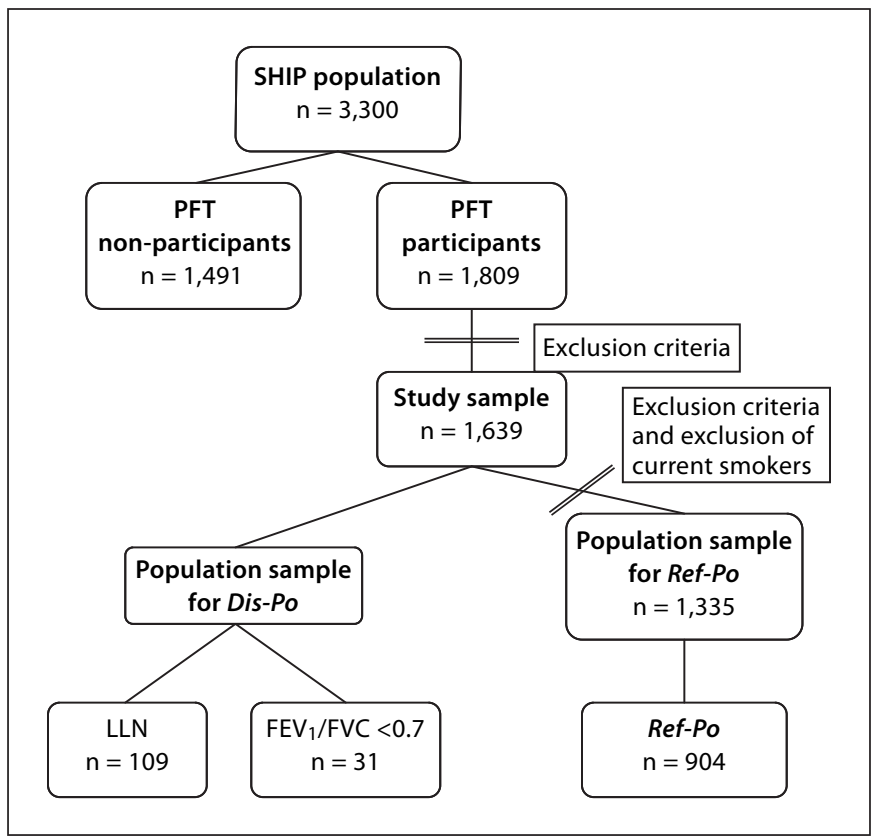

Fig. 1. Study design.

based on, resulting in an ongoing confusion regarding the prevalence and incidence of the disease [3]. The majority of population-based studies have documented a high prevalence of airflow limitation in the general population when applying the definition derived by the Global Initiative for Chronic Obstructive Lung Disease (GOLD) $[4,5]$ and the 2004 standards of the American Thoracic Society/European Respiratory Society for diagnosis and treatment of COPD [1, 6-8]. Several investigators have pointed out that a fixed ratio of forced expiratory volume in $1 \mathrm{~s}\left(\mathrm{FEV}_{1}\right)$ to forced vital capacity (FVC) $<0.7$ will result in an unusually high prevalence in the elderly and a low prevalence in younger individuals [810]. More interestingly, this phenomenon resulted in a falsely high overall prevalence when applying the fixed ratio of $\mathrm{FEV}_{1} / \mathrm{FVC}[6,8,10]$.

Furthermore, the imprecise recommendations for applying values after bronchodilator treatment to describe airflow limitation have encouraged different strategies regarding the evaluation of reversibility. These range from omitting bronchodilator tests, as in the 3rd National Health and Nutrition Examination Survey database [7], the Swiss study on Air Pollution and Lung Diseases in Adults (SAPALDIA) [11] and the European Community Respiratory Health Survey [12], to using sophisticated bronchodilator tests, as in intervention trials [13].
Since different regimens for testing bronchodilator effects will most likely influence the observed prevalence of the disease, Soriano and Mannino [14] proposed a call for simplicity where they suggested using only spirometric results before bronchodilator therapy.

This study aims to gain further insight regarding the prevalence of COPD in a population sample by analyzing airflow limitation based on values before bronchodilator therapy in a well-described, large-scale, population-based survey in northeast Germany - the Study of Health in Pomerania (SHIP). For a better understanding of the impact of the definition in use, two definitions were tested in this population sample containing a comparatively low prevalence of the disease.

\section{Patients and Methods}

\section{Study Design}

Based on a population-based study (SHIP), a stepwise approach was chosen. Firstly, a reference population (Ref-Po) was defined and investigated in order to derive normal values for spirometry. Secondly, volunteers meeting the criteria for COPD by a self-reported physician's diagnosis and/or airflow limitation defined by a fixed ratio of $\mathrm{FEV}_{1} / \mathrm{FVC}<0.7$ or $<5$ th percentile of the reference $\mathrm{FEV}_{1} / \mathrm{FVC}$ ratio as the lower limit of normal defined by $\mathrm{FEV}_{1} / \mathrm{FVC}<5$ th percentile (LLN), i.e. the diseased population (Dis-Po), were analyzed and compared to Ref-Po (fig. 1).

\section{Study Population}

Study volunteers consisted of participants of SHIP, which is a population-based study in a region of northeast Germany. Study details are given elsewhere $[15,16]$. From March 2003 until July 2006, a 5-year follow-up examination was performed (SHIP-1). The sample (without migrated, deceased or non-responding people) consisted of 3,300 subjects (1,584 males and 1,709 females) aged $25-85$ years. Spirometry was performed in a subpopulation of 1,809 volunteers ( 885 males and 924 females). Spirometry was offered and advertised to any subject volunteering in SHIP-1.

All of the participants were examined in health examination centers established for the purpose of the study and all gave written informed consent. The study conformed to the principles of the Declaration of Helsinki and has been approved by the Ethics Committee of the University of Greifswald. All subjects signed a written informed consent.

\section{Diagnostic and Exclusion Criteria}

Information on age, gender, sociodemographic characteristics and medical histories were collected by computer-assisted personal interviews. The medical history was based on the self-reported physician's diagnosis, the use of specific medications, ATC (Anatomical Therapeutic Chemical) code [17], and the electroand echocardiographic pathological findings. All of the clinical tests were performed by experienced, trained and certified physicians. To facilitate comparisons between SHIP and other population-based studies in Germany, external observers were regularly invited to participate in the certification procedures. Data col- 
lection was monitored by a Data Safety and Monitoring Committee.

Smoking status was assessed by self-report and categorized into current, former and never smokers as well as those exposed to passive smoking at home. Pack years (PY) were calculated based on the volunteer's self-report. Subjects who smoked cigars or pipes were not considered. All subjects were asked to quantify their smoking habits into single episodes, each of which was characterized by changes in quantity or cigarette brand. Each episode was quantified in PY and finally added. One PY was defined as smoking 20 cigarettes a day for 1 year.

Dust exposure was estimated based on a patient's self-report. All volunteers were asked about dust exposure due to their occupation. Years of dust exposure were assessed by interview.

Height and weight were measured for the calculation of the body mass index: BMI = body weight $(\mathrm{kg}) /$ height $^{2}\left(\mathrm{~m}^{2}\right)$.

To define the prevalence of COPD by interview, volunteers were asked about a physician's diagnosis of chronic obstructive bronchitis within the last 5 years. To further characterize symptoms due to the disease, volunteers were asked about resting dyspnea and unequivocal shortness of breath at any level of exertion.

Exclusion Criteria for Analysis. Subjects meeting the following exclusion criteria were not included in the analysis: a history of pulmonary diseases other than COPD, myocardial infarction $(n=83)$ or signs of ischemia/infarction in the electrocardiogram, stenosis or insufficiency of the cardiac valves, echocardiographic evidence of systolic and diastolic failure $(n=71)$ or a cardiac pacemaker $(n=7)$. Subjects with missing spirometric values due to technical limitations $(n=9)$ were also excluded. Therefore, data from 1,639 subjects were available for the present study.

Exclusion Criteria for Ref-Po. In order to generate the Ref-Po, subjects were excluded when one of the following additional conditions was fulfilled: chronic obstructive bronchitis, pulmonary disease or emphysema. In addition, subjects receiving at least one medication with cardiovascular, bronchial or anti-allergic/-inflammatory interactions (based on the ATC code) were also not included. The final study population comprised 1,335 healthy volunteers aged $25-85$ years.

\section{Pulmonary Function Testing}

The examinations were conducted using a body plethysmograph equipped with a pneumotachograph (Viasys Healthcare/ Jaeger, Höchberg, Germany) meeting the criteria of the American Thoracic Society [18-20]. The volume signal of the equipment was calibrated with a 3.0-liter syringe connected to the pneumotachograph in accordance with the manufacturer's recommendations, and this was performed at least once on each testing day. Barometric pressure, temperature and relative humidity were registered every morning. Calibration of the volume was examined under ambient temperature pressure conditions, and the integrated volumes were standardized to barometric pressure, body temperature and saturated with water vapor [18-20].

The participants performed at least three lung function maneuvers in order to obtain a minimum of two acceptable and reproducible values [21]. Immediate on-screen error codes indicating the major acceptability (including start, minimal duration and end of test) and reproducibility criteria supported the attempt for standardized procedures. Prior to the tests, the required maneuvers were demonstrated by the operator and the individuals were encouraged and supervised throughout the performance of the tests. The best results for $\mathrm{FVC}$ and $\mathrm{FEV}_{1}$ were taken.

\section{Statistical Analysis}

Analysis of the variance adjusted for sex, height and age was performed in order to evaluate the influence of factors possibly affecting $\mathrm{FVC}, \mathrm{FEV}_{1}$ and $\mathrm{FEV}_{1} / \mathrm{FVC}$. The following variables were statistically tested for possible effects on selected parameters: (1) smoking habits (non-, current, and former smokers); (2) $\beta$-blocker medication, and (3) BMI $\left(<19,19-25,25-30\right.$ and $>30 \mathrm{~kg} / \mathrm{m}^{2}$, based on current WHO classifications) [22].

Prediction equations derived from Ref-Po both for males and females were established by means of quantile regression analysis (a statistical method for estimating models for conditional quantile functions) [23] adjusted for age, gender and height. Age was considered as a continuous variable. Since quantile regression makes no distributional assumption, an initial transformation of the original data was not necessary. Equations are given as the median and the 5 th percentile, whereas the 5 th percentile is generally recommended as LLN $[24,25]$.

According to the GOLD guidelines, the severity of airflow obstruction was classified as stage $\mathrm{I}\left(\mathrm{FEV}_{1}>80 \%\right.$ of predicted), stage II ( $\mathrm{FEV}_{1} 50-80 \%$ of predicted) and stage III/IV ( $\mathrm{FEV}_{1}<50 \%$ predicted) [5].

Continuous variables were expressed as means \pm SD and nominal data were expressed as percentages. A comparison between the Ref-Po and the Dis-Po groups was performed using the MannWhitney $U$ test (continuous data) and the $\chi^{2}$ test (nominal data). A value of $\mathrm{p}<0.05$ was considered statistically significant. To assess the sensitivity of our results to non-response, we applied statistical weights. The weights accounted for non-response to SHIP-1 and for participation in spirometry versus overall population based on sociodemographic and health-related variables. Robust standard errors were computed for all weighted analyses. We found no significant differences in our results. Subsequent analyses were therefore conducted without statistical weights. Statistical analyses were performed with SAS 9.1 software (SAS Institute, Cary, N.C., USA).

\section{Results}

The characteristics of the complete study population are shown in table 1 . The mean age of the participants was $52.3 \pm 13.7$ years. After applying the exclusion criteria for Ref-Po and Dis-Po, the final study population consisted of 1,639 volunteers.

According to their smoking habits, we found a significant difference between the participants performing pulmonary function testing (PFT) and the non-PFT participants, with fewer non-smoking participants in the PFT group [never smokers: $\mathrm{n}=583$ (39.5\%) vs. 787 (43.5\%); ex-smokers: $n=413$ (28\%) vs. 431 (23.8\%), and current smokers: $\mathrm{n}=481(32.6 \%)$ vs. 590 (32.6\%); $\mathrm{p}<$ 0.01]. However, there was no difference concerning selfreported COPD, occupational dust exposure and COPDrelated symptoms. With respect to the BMI status, no 
Table 1. Descriptive data of the 1,809 participants who underwent PFT

\begin{tabular}{|c|c|c|c|c|c|c|c|c|c|}
\hline & $\mathrm{n}$ & $\%$ & $\begin{array}{l}\text { Height } \\
\mathrm{cm}\end{array}$ & $\begin{array}{l}\text { Weight } \\
\mathrm{kg}\end{array}$ & $\begin{array}{l}\text { Current } \\
\text { smokers, \% }\end{array}$ & $\begin{array}{l}\text { Active } \\
\text { smokers, PY }\end{array}$ & $\begin{array}{l}\mathrm{FEV}_{1} \\
\text { liters }\end{array}$ & $\begin{array}{l}\text { FVC } \\
\text { liters }\end{array}$ & $\mathrm{FEV}_{1} / \mathrm{FVC}$ \\
\hline \multicolumn{10}{|l|}{ Males } \\
\hline 25-34 years & 96 & 10.8 & $180.4 \pm 6.3$ & $86.1 \pm 15.0$ & $42.7(41)$ & $8.6 \pm 5.2$ & $4.6 \pm 0.6$ & $5.4 \pm 0.8$ & $0.85 \pm 0.06$ \\
\hline $35-44$ years & 186 & 21.0 & $179.0 \pm 5.7$ & $87.3 \pm 13.5$ & 31.7 (59) & $16.2 \pm 8.0$ & $4.4 \pm 0.7$ & $5.1 \pm 0.8$ & $0.85 \pm 0.05$ \\
\hline $45-54$ years & 182 & 20.6 & $177.0 \pm 5.8$ & $90.5 \pm 16.0$ & $36.8(67)$ & $26.3 \pm 13.5$ & $3.9 \pm 0.6$ & $4.6 \pm 0.7$ & $0.84 \pm 0.07$ \\
\hline 55-64 years & 202 & 22.8 & $174.9 \pm 6.0$ & $87.3 \pm 13.1$ & $18.8(38)$ & $30.3 \pm 12.0$ & $3.6 \pm 0.7$ & $4.3 \pm 0.7$ & $0.84 \pm 0.08$ \\
\hline $65-74$ years & 159 & 18.0 & $172.8 \pm 6.0$ & $87.7 \pm 14.3$ & $8.2(13)$ & $30.7 \pm 17.0$ & $3.1 \pm 0.5$ & $3.8 \pm 0.6$ & $0.83 \pm 0.06$ \\
\hline$\geq 75$ years & 60 & 6.8 & $170.4 \pm 6.5$ & $80.9 \pm 12.7$ & $8.5(5)$ & $29.2 \pm 17.7$ & $2.3 \pm 0.6$ & $3.0 \pm 0.6$ & $0.76 \pm 0.10$ \\
\hline Total & 885 & 100 & $176.1 \pm 6.6$ & $87.5 \pm 14.4$ & $25.2(223)$ & $21.3 \pm 13.5$ & $3.8 \pm 0.9$ & $4.5 \pm 1.0$ & $0.84 \pm 0.07$ \\
\hline \multicolumn{10}{|l|}{ Females } \\
\hline 25-34 years & 110 & 11.9 & $166.4 \pm 6.3$ & $68.1 \pm 14.8$ & $34.6(38)$ & $6.9 \pm 4.1$ & $3.5 \pm 0.5$ & $4.0 \pm 0.6$ & $0.88 \pm 0.06$ \\
\hline $35-44$ years & 187 & 20.2 & $166.4 \pm 6.1$ & $71.0 \pm 12.9$ & $35.3(66)$ & $11.7 \pm 7.1$ & $3.2 \pm 0.5$ & $3.8 \pm 0.5$ & $0.86 \pm 0.06$ \\
\hline $45-54$ years & 218 & 23.6 & $164.7 \pm 6.5$ & $75.3 \pm 14.7$ & $27.1(59)$ & $15.0 \pm 9.2$ & $2.9 \pm 0.5$ & $3.4 \pm 0.5$ & $0.86 \pm 0.05$ \\
\hline 55-64 years & 230 & 24.9 & $162.1 \pm 5.5$ & $75.8 \pm 14.6$ & $13.9(32)$ & $14.2 \pm 8.3$ & $2.6 \pm 0.4$ & $3.0 \pm 0.5$ & $0.85 \pm 0.06$ \\
\hline $65-74$ years & 151 & 16.3 & $160.2 \pm 5.9$ & $74.2 \pm 12.2$ & $8.0(12)$ & $23.6 \pm 9.3$ & $2.2 \pm 0.4$ & $2.6 \pm 0.5$ & $0.85 \pm 0.06$ \\
\hline$\geq 75$ years & 28 & 3.0 & $155.7 \pm 7.0$ & $72.0 \pm 12.4$ & $3.6(1)$ & 25.8 & $1.8 \pm 0.4$ & $2.2 \pm 0.5$ & $0.82 \pm 0.06$ \\
\hline Total & 924 & 100 & $163.6 \pm 6.6$ & $73.4 \pm 14.1$ & $22.5(208)$ & $12.8 \pm 8.5$ & $2.8 \pm 0.6$ & $3.3 \pm 0.7$ & $0.86 \pm 0.06$ \\
\hline
\end{tabular}

$\mathrm{n}=$ Absolute number of participants.

Table 2. Equations for predicting lung function derived from 904 healthy volunteers (Ref-Po)

\begin{tabular}{cll}
\hline Variable & Percentile & Equation \\
\hline Females & & \\
FVC & 5th & $-1.7229-0.0180 \times \mathrm{A}+0.0348 \times \mathrm{H}-0.000116 \times \mathrm{A}^{2}$ \\
& Median & $14.4053+0.0268 \times \mathrm{A}-0.1901 \times \mathrm{H}-0.000307 \times \mathrm{A} \times \mathrm{H}+0.000793 \times \mathrm{H}^{2}$ \\
FEV $_{1}$ & 5 th & $-0.6021-0.0280 \times \mathrm{A}+0.0266 \times \mathrm{H}$ \\
& Median & $-2.560-0.0236 \times \mathrm{A}+0.0408 \times \mathrm{H}$ \\
$\mathrm{FEV}_{1} / \mathrm{FVC}$ & 5th & $1.1838+0.0039 \times \mathrm{A}-0.0029 \times \mathrm{H}-0.004629 \times 10^{-2} \times \mathrm{A}^{2}$ \\
& Median & $1.1107-0.0007 \times \mathrm{A}-0.0013 \times \mathrm{H}$ \\
\hline Males $_{\mathrm{FVC}}$ & 5th & $-5.1571+0.0561 \times \mathrm{A}+0.0459 \times \mathrm{H}-0.000765 \times \mathrm{A}^{2}$ \\
& Median & $-34.1599+0.1064 \times \mathrm{A}+0.3507 \times \mathrm{H}-0.000767 \times \mathrm{A} \times \mathrm{H}-0.000694 \times \mathrm{H}^{2}$ \\
$\mathrm{FEV}_{1}$ & 5th & $-4.2733-0.0271 \times \mathrm{A}+0.0496 \times \mathrm{H}$ \\
$\mathrm{FEV}_{1} / \mathrm{FVC}$ & Median & $-4.6916-0.0266 \times \mathrm{A}+0.0567 \times \mathrm{H}$ \\
& Median & $0.2851+0.0106 \times \mathrm{A}+0.0013 \times \mathrm{H}-0.000109 \times \mathrm{A}^{2}$ \\
& Median & $0.7997-0.0008 \times \mathrm{A}+0.0005 \times \mathrm{H}$ \\
\hline
\end{tabular}

Prediction equations derived from age $(\mathrm{A})$ in years and height $(\mathrm{H})$ in $\mathrm{cm}$. Ranges of 25-85 years for age.

significant difference was found between the PFT participants and the non-PFT participants $(\mathrm{p}=0.14)$. Sensitivity analysis using statistical weights comparing participants in spirometry to the overall SHIP-1 population revealed robust results. Participant belonged either to Ref-Po or to Dis-Po.

Airflow Limitation in a German Study Cohort

\section{Reference Population (Ref-Po)}

The following factors were tested for their influence on FVC, $\mathrm{FEV}_{1}$ and $\mathrm{FEV}_{1} / \mathrm{FVC}$, with adjustments for sex, height and age by analysis of variance.

Current smokers had significantly different values compared to former smokers and non-smokers. There

Respiration 2010;80:292-300 
Table 3. Prevalence of COPD and risk factors assessed by interview for the total study population, the PFT volunteers and the functionally diseased subjects

\begin{tabular}{|c|c|c|c|c|c|c|c|c|c|}
\hline \multirow[t]{2}{*}{ No PFT } & $\begin{array}{l}\text { PFT } \\
\text { completed }\end{array}$ & \multirow[t]{2}{*}{$\mathrm{p}$} & $\begin{array}{l}\text { Total study } \\
\text { sample }\end{array}$ & \multicolumn{3}{|c|}{$\mathrm{FEV}_{1} / \mathrm{FVC}<0.7$} & \multicolumn{3}{|c|}{$\mathrm{FEV}_{1} / \mathrm{FVC}<\mathrm{LLN}$} \\
\hline & $(\mathrm{n}=1,809)$ & & $(\mathrm{n}=1,639)$ & $\begin{array}{l}\text { all } \\
(\mathrm{n}=31)\end{array}$ & $\begin{array}{l}\text { age } \\
\geq 40 \text { years } \\
(\mathrm{n}=29)\end{array}$ & $\begin{array}{l}\text { age } \\
\geq 65 \text { years } \\
(\mathrm{n}=13)\end{array}$ & $\begin{array}{l}\text { all } \\
(\mathrm{n}=109)\end{array}$ & $\begin{array}{l}\text { age } \\
\geq 40 \text { years } \\
(\mathrm{n}=91)\end{array}$ & $\begin{array}{l}\text { age } \\
\geq 65 \text { years } \\
(\mathrm{n}=18)\end{array}$ \\
\hline
\end{tabular}

\section{Interview}

Chronic obstructive bronchitis $\quad 6.3$

Shortness of breath (any reason) 22.8

Chronic obstructive bronchitis

and shortness of breath

Occupational dust exposure

$\begin{array}{ccccllllll}6.3 & 4.8 & 0.06 & 4.4 & 19.4 & 20.7 & 38.5 & 12.8 & 14.3 & 27.8 \\ 22.8 & 19.5 & 0.02 & 18.0 & 38.7 & 41.4 & 61.5 & 25.7 & 26.4 & 66.7 \\ & & & & & & & & & \\ 3.7 & 2.9 & 0.19 & 2.5 & 16.1 & 17.2 & 30.8 & 10.1 & 11.0 & 27.8 \\ 20.4 & 19.5 & 0.28 & 18.7 & 19.4 & 20.7 & 23.1 & 24.3 & 24.4 & 16.7 \\ 17 \pm 12.8 & 15 \pm 12.4 & 0.07 & 14 \pm 12.3 & 10 \pm 9.3 & 10 \pm 9.3 & 3 \pm 1.2 & 15 \pm 10.2 & 17 \pm 10.2 & 12 \pm 16.2 \\ 16 \pm 13.2 & 14 \pm 11.9 & <0.01 & 12.9 \pm 11.3 & 21 \pm 17.3 & 22 \pm 17.3 & 25 \pm 17.7 & 13 \pm 14.7 & 15 \pm 15.5 & 29 \pm 17.5\end{array}$

Dust exposure, years

Smoking exposure, PY

Data are percentages or means $\left( \pm\right.$ SD). The $\chi^{2}$ test (nominal data) and Mann-Whitney test (interval data) were used. PY $=$ PY of ex- and current smokers.

Table 4. Prevalence and distribution of volunteers with airway obstruction (Dis-Po) according to the severity of disease

\begin{tabular}{|c|c|c|c|c|c|c|c|c|}
\hline \multirow[t]{2}{*}{ Study population } & \multicolumn{4}{|c|}{$\mathrm{FEV}_{1} / \mathrm{FVC}<0.7$} & \multicolumn{4}{|c|}{$\mathrm{FEV}_{1} / \mathrm{FVC}<\mathrm{LLN}$} \\
\hline & $\begin{array}{l}\text { all } \\
(\mathrm{n}=1,639)\end{array}$ & $\begin{array}{l}\text { age } \\
<40 \text { years } \\
(\mathrm{n}=382)\end{array}$ & $\begin{array}{l}\text { age } \\
\geq 40 \text { years } \\
(\mathrm{n}=1,257)\end{array}$ & $\begin{array}{l}\text { age } \\
\geq 65 \text { years } \\
(n=306)\end{array}$ & $\begin{array}{l}\text { all } \\
(\mathrm{n}=1,639)\end{array}$ & $\begin{array}{l}\text { age } \\
<40 \text { years } \\
(\mathrm{n}=382)\end{array}$ & $\begin{array}{l}\text { age } \\
\geq 40 \text { years } \\
(\mathrm{n}=1,257)\end{array}$ & $\begin{array}{l}\text { age } \\
\geq 65 \text { years } \\
(\mathrm{n}=306)\end{array}$ \\
\hline All & $1.9(31)$ & $0.5(2)$ & $2.3(29)$ & $4.2(13)$ & $6.7(109)$ & $4.7(18)$ & $7.2(91)$ & $5.9(18)$ \\
\hline Stage I & 0.1 & - & 0.1 & 0.3 & 2.7 & 3.1 & 2.6 & 1.3 \\
\hline Stage II & 1.4 & 0.5 & 1.7 & 2.3 & 3.5 & 1.6 & 4.6 & 2.9 \\
\hline Stage III/IV & 0.4 & - & 0.5 & 1.6 & 0.4 & - & - & 1.6 \\
\hline Males $(\mathrm{n}=783)$ & $2.6(20)$ & - & $2.6(20)$ & $7.2(12)$ & $6.6(52)$ & $3.7(7)$ & $7.6(45)$ & $6.6(11)$ \\
\hline Stage I & 0.26 & - & 0.26 & 0.6 & 3.2 & 3.1 & 3.6 & 0.6 \\
\hline Stage II & 1.8 & - & 1.8 & 4.2 & 2.9 & 1.1 & 3.5 & 3.6 \\
\hline Stage III/IV & 0.5 & - & 0.5 & 2.4 & 0.5 & - & 0.7 & 9.6 \\
\hline Females $(n=856)$ & $1.3(11)$ & $0.5(2)$ & $0.7(9)$ & $0.7(1)$ & $6.7(57)$ & $5.6(11)$ & $7.0(46)$ & $5.0(7)$ \\
\hline Stage I & - & - & - & - & 2.3 & 3.6 & 2.0 & 2.1 \\
\hline Stage II & 1 & 0.5 & 0.6 & - & 4.1 & 2.1 & 4.7 & 2.1 \\
\hline Stage III/IV & 0.2 & - & 0.2 & 0.7 & 0.2 & - & 0.3 & 0.7 \\
\hline
\end{tabular}

Data show prevalences in percent $(\mathrm{n})$. Stage $1=\mathrm{FEV}_{1}>80 \%$ of predicted, stage $\mathrm{II}=\mathrm{FEV}_{1} 80-50 \%$ of predicted; stage III $/ \mathrm{IV}=\mathrm{FEV}$ $<50 \%$ of predicted.

was no difference between the non- and former smokers. Consequently, current smokers were excluded from the study. $\beta$-Blocker medication and BMI had no significant impact. In conclusion, in addition to the exclusion criteria for Ref-Po, current smokers ( $\mathrm{n}=431,23.8 \%$ ) were excluded. The final Ref-Po sample comprised 904 (439 males and 465 females) of the initial 1,809 participants.
The derived prediction equations for the female and male individuals are given in table 2 .

\section{Prevalence of Airflow Limitation (Dis-Po)}

The prevalence as well as the age distribution of symptomatic and asymptomatic airflow limitation, based on participants' self-reports, is shown in table 3. Almost $40 \%$ of the patients with airflow limitation defined by the 
Table 5. Demographic characteristics and smoking habits of volunteers with airway obstruction

\begin{tabular}{|c|c|c|c|c|}
\hline \multirow[t]{2}{*}{ PFT group } & \multicolumn{2}{|c|}{$\mathrm{FEV}_{1} / \mathrm{FVC}<0.7$} & \multicolumn{2}{|c|}{$\mathrm{FEV}_{1} / \mathrm{FVC}<\mathrm{LLN}$} \\
\hline & all & $\begin{array}{l}\text { age } \\
\geq 40 \text { years }\end{array}$ & all & $\begin{array}{l}\text { age } \\
\geq 40 \text { years }\end{array}$ \\
\hline All & $\mathrm{n}=31$ & $\mathrm{n}=29$ & $\mathrm{n}=109$ & $\mathrm{n}=91$ \\
\hline Age, years & $63(14.0)$ & $65(12.3)$ & $52(12.5)$ & $55(10.7)$ \\
\hline \multicolumn{5}{|l|}{ Smokers } \\
\hline Never smokers & 23 & 21 & 34 & 35 \\
\hline Ex-smokers & 39 & 38 & 43 & 42 \\
\hline Current smokers & 39 & 41 & 23 & 23 \\
\hline PY & $27(14.7)$ & $28(14.7)$ & $21(13.5)$ & $23(13.5)$ \\
\hline Passive smoking & 13 & 10 & 26 & 22 \\
\hline Males & $\mathrm{n}=20$ & $\mathrm{n}=20$ & $\mathrm{n}=52$ & $\mathrm{n}=45$ \\
\hline Age, years & $69(10.3)$ & $69(10.3)$ & $54(13.6)$ & $57(11.9)$ \\
\hline \multicolumn{5}{|l|}{ Smokers } \\
\hline Never smokers & 15 & 15 & 27 & 27 \\
\hline Ex-smokers & 30 & 30 & 42 & 40 \\
\hline Current smokers & 55 & 55 & 31 & 33 \\
\hline PY & $29(16.4)$ & $29(16.4)$ & $26(14.5)$ & $28(14.1)$ \\
\hline Passive smoking & 5 & 5 & 17 & 18 \\
\hline Females & $\mathrm{n}=11$ & $\mathrm{n}=9$ & $\mathrm{n}=57$ & $\mathrm{n}=46$ \\
\hline Age, years & $51(11.8)$ & $54(10.0)$ & $50(11.2)$ & $53(9.2)$ \\
\hline \multicolumn{5}{|l|}{ Smokers } \\
\hline Never smokers & 36 & 33 & 40 & 43 \\
\hline Ex-smokers & 55 & 56 & 44 & 43 \\
\hline Current smokers & 9 & 11 & 16 & 13 \\
\hline PY & $22(7.7)$ & $23(7.4)$ & $15(9.2)$ & $17(9.3)$ \\
\hline Passive smoking & 27 & 22 & 33 & 26 \\
\hline
\end{tabular}

Data are percentages or means $( \pm S D) . P Y=P Y$ for current and ex-smokers.

fixed ratio of $\mathrm{FEV}_{1} / \mathrm{FVC}$ complained of dyspnea. This percentage was smaller when the LLN of $\mathrm{FEV}_{1} / \mathrm{FVC}$ was applied. In approximately $40 \%$ of the patients with either one of the spirometric definitions of airflow limitation and dyspnea, airflow limitation had been previously diagnosed. The majority of volunteers with airflow limitation were $>40$ years $\left(\mathrm{FEV}_{1} / \mathrm{FVC}<0.7: 94 \%\right.$ and $\mathrm{LLN}$ : 83\%). Applying the fixed ratio of $\mathrm{FEV}_{1} / \mathrm{FVC}<0.7$, the prevalence of airflow limitation was 1.9\% (2.3\% for volunteers $\geq 40$ years), whereas the prevalence was significantly higher $(6.7$ and $7.2 \%$, respectively; both $\mathrm{p}<0.001$ ) when the LLN was applied. In 81 of 109 (74.3\%) subjects with decreased LLN, the $\mathrm{FEV}_{1} / \mathrm{FVC}$ ratio was $>0.7$ ( $\geq 40$ years $65 / 91 ; 71.4 \%)$.

The distribution of volunteers with airflow limitation according to their GOLD stage is given in table 4. Smoking habits are demonstrated in table 5. Applying the def- inition of LLN and focusing on volunteers $\geq 40$ years, $35 \%$ of the subjects with airflow limitation were never smokers (27\% males and $43 \%$ females).

\section{Discussion}

The key findings of this large-scale population-based survey are that the prevalence of airflow limitation is largely dependent on the definition when applied in an area with a relatively low COPD prevalence. The fixed ratio of $\mathrm{FEV}_{1} / \mathrm{FVC}<0.7$, as previously used in several population-based studies $[11,12]$, results in a prevalence of $1.9 \%$ in the overall population. In contrast, applying the LLN to define airflow limitation reveals a fourfold increase in the prevalence, up to $7.2 \%$ in volunteers aged $\geq 40$. The prevalence data for airflow limitation collected in our study are lower than those established in other central European cohorts.

Our study results further support the hypothesis that the prevalence of airflow limitation is not a biological constant but instead highly dependent on its functional definition. A number of studies have shown significant differences in the prevalence of airflow limitation and $\mathrm{COPD}$ when applying the fixed ratio of $\mathrm{FEV}_{1} / \mathrm{FVC}$ or the LLN defined by the 5th percentile. Hansen et al. [10] have demonstrated that the use of the fixed ratio of $\mathrm{FEV}_{1} / \mathrm{FVC}$ will lead to an underdiagnosis of airflow limitation in young and an overestimation in older individuals. However, their study shows methodological differences compared to our survey, since only disease-free individuals were included. Data collected within SAPALDIA revealed comparable potencies of both, LLN and fixed ratio, corrected for $\mathrm{FEV}_{1}$ decline, concerning symptoms and health care utilization [26]. A fixed ratio of $\mathrm{FEV}_{1} /$ FVC was shown to be the most accurate for defining subjects at the 5th decade, independent of smoking [10]. Comparable data have been published by Swanney et al. [8], with a trend towards younger ages having a more accurate application of the fixed ratio. Data from Bergen, Norway, have shown that using the fixed ratio of $\mathrm{FEV}_{1} /$ FVC in adults $\geq 70$ years of age will lead to an overdiagnosis by $35 \%$, with an increasing rate up to $50 \%$ in subjects $>80$ years of age [9]. Finally, all these studies showed an increase in the prevalence of COPD when applying the fixed ratio of $\mathrm{FEV}_{1} / \mathrm{FVC}$. The data collected within our population-based survey contrast the results reported by others. First, the magnitude for which airflow limitation was undiagnosed by the fixed ratio of $\mathrm{FEV}_{1} / \mathrm{FVC}$ is markedly higher in northeast Germany. Second, we did not 
demonstrate a cutoff of accuracy between underdiagnosing young adults and overdiagnosing older adults, since the 5 th percentile barely reached an $\mathrm{FEV}_{1} / \mathrm{FVC}$ ratio of 0.7 for all age decades. Third, and most important, with the exception of men aged $>65$ years, applying the LLN increased - rather than decreased - the prevalence of COPD. This phenomenon most likely contributes to population-specific factors. Extrapolating the impact of both definitions on the overall SHIP target population of 220,000 inhabitants, the estimated proportion of diseased people would increase from 3,520 to 14,740 cases. This effect size is even more pronounced in subjects $<40$ years [15].

In our study, means as well as the LLN of $\mathrm{FEV}_{1} / \mathrm{FVC}$ derived are higher in comparison to reference equations presented by SAPALDIA [27] and the National Health and Nutrition Examination Survey [7]. This explains the low sensitivity in diagnosing airflow limitation using the fixed ratio of $\mathrm{FEV}_{1} / \mathrm{FVC}$ in Pomerania.

The main difference between our results and the data discussed above is the relatively low prevalence of airflow limitation. To set our results in perspective, comparisons to data reported by the BOLD study are mandatory $[1$, 28-30]. In this study, airflow limitation in COPD was exclusively defined by a fixed ratio of $\mathrm{FEV}_{1} / \mathrm{FVC}<0.7$ after bronchodilation, resulting in a prevalence ranging from 13.3 to $26.1 \%$ in Europe and 11.4 to $26.1 \%$ in the overall study population [1]. The local study samples ranged from 563 to 1,349 volunteers, with response proportions ranging from 14 to $87 \%$ (SHIP: $59 \%$ of all SHIP participants volunteered in PFT; $\mathrm{n}=1,809)$. The prevalence reported in European surveys based on results before bronchodilation also revealed significantly higher COPD rates (SAPALDIA-I 10\% and European Community Respiratory Health Survey 11.8\%) [11, 12].

One obvious reason for the significantly lower prevalence appears to be related to smoking habits. The geographical location of SHIP is at best described as mixed, consisting of rural participants and volunteers from midsized towns. Differences between rural and urban areas concerning smoking habits are well known in Germany, with metropolitan regions having higher proportions of current smokers than rural regions [31]. Even with a relatively high proportion of smokers in our study ( $45 \% \mathrm{fe}$ males and $24 \%$ males), the PY number is obviously lower compared with other populations $[1,29,32,33]$. The high percentage of smokers in northeast Germany is contrasted by a smaller number of cigarettes smoked daily as well as by a higher age when individuals start smoking [31, 34]. The years of occupational dust exposure and second- hand smoking are comparable with those reported by others $[1,35]$. The extent to which geographical circumstances can additionally explain the low prevalence (SHIP is located at a coastal region of the Baltic Sea) cannot be answered by our study.

In our study, spirometric results were obtained before bronchodilation. The effect of values measured after bronchodilation on individual airflow limitation due to COPD is evident [5, 36-38]. However, there is no general agreement regarding the methodology since the obtained results suffer from limited comparability [14]. Using values before bronchodilation in the general population will result in an overestimation of COPD $[36,38]$. However, the prevalence of airflow limitation was relatively low in our study population. The statistical significance of values obtained after bronchodilation would most likely further decrease the prevalence of COPD.

In good agreement with results from other studies, COPD is a significantly underdiagnosed disease $[28,29]$. Applying the LLN to define airflow limitation, only $14.3 \%$ of adults aged $\geq 40$ years had already been diagnosed, although $26.4 \%$ complained of symptoms. Furthermore, the discrepancy between definite symptoms of airflow limitation and already diagnosed disease increases with decreasing age. This further confirms a need for education and information concerning COPD in both populations and health care settings [39].

The major strength of our survey is the high quality of the investigations applied within a cross-sectional, population-based design, guaranteed by several established quality insurance measures and a high level of standardization. The reference equation derived in our study is based on well-described and extensively examined healthy subjects, submitted to echocardiography, interviews and exercise testing to mention just a few. However, our study also has certain limitations. As with any population-based cohort study, participation in the SHIP study, in particular in the PFT, was entirely voluntary, thus possibly resulting in a selection bias towards younger and healthier subjects. Comparing the PFT of volunteers to the overall population, a trend towards younger age, lower BMI and less smokers was obvious. However, there was no difference in the self-reported physician's diagnosis of COPD, dust exposure and symptoms. Statistical weights including smoking habits showed robust results. Even if the demographic differences between the PFT volunteers and the overall population were rather small, we cannot definitely eliminate possible effects that may have biased the prevalence estimates of airway obstruction assessed by PFT in our study. Finally, the results 
need to be confirmed by larger studies with a minimal selection bias.

In summary, this study shows the high impact of the applied definition of airflow limitation on the prevalence of COPD in a large-scale, population-based survey. We assume that extrapolating our data to other populationbased studies will significantly modify the reported prevalence rates. Furthermore, using the LLN to describe normalcy could provide a more sensitive tool to identify patients with airflow limitation. Since the differences in applying the fixed ratio of $\mathrm{FEV}_{1} / \mathrm{FVC}$ or the LLN to describe the prevalence of airflow limitation appear to be population-specific factors, locally derived reference values should be assessed.

\section{Acknowledgments}

SHIP is part of the Community Medicine Net of the University of Greifswald, which is funded by grants from the German Federal Ministry of Education and Research for SHIP (BMBF, grants 01ZZ96030 and 01ZZ0701) and Kompetenznetz Asthma/ COPD (Competence Network Asthma/COPD; FKZ 01GI08810888), the Ministry of Education, Research and Cultural Affairs, and the Ministry of Social Affairs of the Federal State of Mecklenburg-West Pomerania. All the contributors who helped in the data collection are gratefully acknowledged.

\section{References}

1 Buist AS, McBurnie MA, Vollmer WM, Gillespie S, Burney P, Mannino DM, Menezes AM, Sullivan SD, Lee TA, Weiss KB, Jensen RL, Marks GB, Gulsvik A, NizankowskaMogilnicka E: International variation in the prevalence of COPD (the BOLD study): a population-based prevalence study. Lancet 2007;370:741-750.

-2 Lin HH, Murray M, Cohen T, Colijn C, Ezzati M: Effects of smoking and solid-fuel use on COPD, lung cancer, and tuberculosis in china: a time-based, multiple risk factor, modelling study. Lancet 2008;372:14731483.

-3 Pellegrino R, Brusasco V, Viegi G, Crapo RO, Burgos F, Casaburi R, Coates A, van der Grinten CP, Gustafsson P, Hankinson J, Jensen R, Johnson DC, Macintyre N, McKay R, Miller MR, Navajas D, Pedersen OF, Wanger J: Definition of COPD: based on evidence or opinion? Eur Respir J 2008;31:681-682.

4 Pauwels RA, Buist AS, Calverley PM, Jenkins CR, Hurd SS: Global strategy for the diagnosis, management, and prevention of chronic obstructive pulmonary disease. NHLBI/ WHO Global Initiative for Chronic Obstructive Lung Disease (GOLD) Workshop Summary. Am J Respir Crit Care Med 2001;163: 1256-1276.

5 Global Initiative for Obstructive Lung Disease: Global Strategy for the Diagnosis, Management, and Prevention of Chronic Obstructive Pulmonary Disease - Update 2008. http://www.goldcopd.com/.

6 Mannino DM, Ford ES, Redd SC: Obstructive and restrictive lung disease and functional limitation: data from the Third $\mathrm{Na}$ tional Health and Nutrition Examination. J Intern Med 2003;254:540-547.
7 Hankinson JL, Odencrantz JR, Fedan KB: Spirometric reference values from a sample of the general U.S. population. Am J Respir Crit Care Med 1999;159:179-187.

-8 Swanney MP, Ruppel G, Enright PL, Pedersen OF, Crapo RO, Miller MR, Jensen RL, Falaschetti E, Schouten JP, Hankinson JL, Stocks J, Quanjer PH: Using the lower limit of normal for the $\mathrm{FEV}_{1} / \mathrm{FVC}$ ratio reduces the misclassification of airway obstruction. Thorax 2008;63:1046-1051.

-9 Hardie JA, Buist AS, Vollmer WM, Ellingsen I, Bakke PS, Morkve O: Risk of over-diagnosis of COPD in asymptomatic elderly neversmokers. Eur Respir J 2002;20:1117-1122.

10 Hansen JE, Sun XG, Wasserman K: Spirometric criteria for airway obstruction: use percentage of $\mathrm{FEV}_{1} / \mathrm{FVC}$ ratio below the fifth percentile, not $<70 \%$. Chest 2007;131:349355.

11 Brutsche MH, Downs SH, Schindler C, Gerbase MW, Schwartz J, Frey M, Russi EW, Ackermann-Liebrich U, Leuenberger P, SAPALDIA Team: Bronchial hyperresponsiveness and the development of asthma and COPD in asymptomatic individuals: SA PALDIA cohort study. Thorax 2006;61:671677.

12 de Marco R, Accordini S, Cerveri I, Corsico A, Sunyer J, Neukirch F, Kunzli N, Leynaert B, Janson C, Gislason T, Vermeire P, Svanes C, Anto JM, Burney P: An international survey of chronic obstructive pulmonary disease in young adults according to GOLD stages. Thorax 2004;59:120-125.

13 Tashkin DP, Celli B, Decramer M, Liu D, Burkhart D, Cassino C, Kesten S: Bronchodilator responsiveness in patients with COPD. Eur Respir J 2008;31:742-750.

-14 Soriano JB, Mannino DM: Reversing concepts on COPD irreversibility. Eur Respir J 2008;31:695-696.
15 John U, Greiner B, Hensel E, Ludemann J, Piek M, Sauer S, Adam C, Born G, Alte D, Greiser E, Haertel U, Hense HW, Haerting J, Willich S, Kessler C: Study of health in Pomerania (SHIP): a health examination survey in an east German region: objectives and design. Soz Praventivmed 2001;46:186194.

16 Koch B, Schaper C, Ittermann T, Spielhagen T, Dorr M, Volzke H, Opitz CF, Ewert R, Glaser S: Reference values for cardiopulmonary exercise testing in healthy volunteers: the SHIP study. Eur Respir J 2009;33:389-397.

17 WHO: ATC Index with DDDS. Guidelines for ATC Classification and DDD assignment. Oslo, WHO Collaborating Centre for Drug Statistics Methodology, 2008

18 Standardization of spirometry - 1987 update. Statement of the American Thoracic Society. Am Rev Respir Dis 1987;136:12851298.

19 Standardization of spirometry - 1987 update. Official statement of American Thoracic Society. Respir Care 1987;32:10391060

20 Nelson SB, Gardner RM, Crapo RO, Jensen RL: Performance evaluation of contemporary spirometers. Chest 1990;97:288-297.

21 Quanjer PH, Tammeling GJ, Cotes JE, Pedersen OF, Peslin R, Yernault JC: Lung volumes and forced ventilatory flows. Report Working Party Standardization of Lung Function Tests, European Community for Steel and Coal. Official Statement of the European Respiratory Society. Eur Respir J 1993;16(suppl):5-40.

22 Measuring Obesity - Classification and Description of Anthropometric Data. Report on a WHO Consultation of the Epidemiology of Obesity. Warsaw, World Health Organization, 1987. 
23 Koenker R: Quantile Regression. Econometric Society Monographs. New York, Cambridge University Press, 2005.

24 Miller MR, Pincock AC: Predicted values: how should we use them? Thorax 1988;43: 265-267.

25 Dixon WJ, Massey FJ Jr: Introduction to Statistical Analysis, ed 3. New York, McGrawHill, 1969, pp 461-463.

26 Bridevaux PO, Gerbase MW, Probst-Hensch NM, Schindler C, Gaspoz JM, Rochat T: Long-term decline in lung function, utilisation of care and quality of life in modified GOLD stage 1 COPD. Thorax 2008;63:768774.

27 Kuster SP, Kuster D, Schindler C, Rochat MK, Braun J, Held L, Brandli O: Reference equations for lung function screening of healthy never-smoking adults aged 18-80 years. Eur Respir J 2008;31:860-868.

-28 Schirnhofer L, Lamprecht B, Vollmer WM, Allison MJ, Studnicka M, Jensen RL, Buist AS: COPD prevalence in Salzburg, Austria: results from the burden of obstructive lung disease (BOLD) study. Chest 2007;131:2936.

-29 Geldmacher H, Biller H, Herbst A, Urbanski K, Allison M, Buist AS, Hohlfeld JM, Welte $\mathrm{T}$ : The prevalence of chronic obstructive pulmonary disease (COPD) in Germany. Results of the BOLD study (in German). Dtsch Med Wochenschr 2008;133:2609-2614.
30 Buist AS, Vollmer WM, Sullivan SD, Weiss KB, Lee TA, Menezes AM, Crapo RO, Jensen RL, Burney PG: The burden of obstructive lung disease initiative (BOLD): rationale and design. COPD 2005;2:277-283.

31 Volzke H, Neuhauser H, Moebus S, Baumert J, Berger K, Stang A, Ellert U, Werner A, Doring A: Urban-rural disparities in smoking behaviour in Germany. BMC Public Health 2006;6:146.

32 Nizankowska-Mogilnicka E, Mejza F, Buist AS, Vollmer WM, Skucha W, Harat R, Pajak A, Gasowski J, Frey J, Nastalek P, Twardowska M, Janicka J, Szczeklik A: Prevalence of COPD and tobacco smoking in Malopolska region - results from the BOLD study in Poland. Pol Arch Med Wewn 2007;117:402410.

33 McCurdy SA, Sunyer J, Zock JP, Anto JM, Kogevinas M: Smoking and occupation from the European Community Respiratory Health Survey. Occup Environ Med 2003;60: 643-648.

34 Volzke H, Neuhauser H, Moebus S, Baumert J, Berger K, Stang A, Ellert U, Werner A, Döring A: Rauchen: Regionale Unterschiede in Deutschland. Dtsch Arztebl 2006;103: 2784-2790.
35 Yin P, Jiang CQ, Cheng KK, Lam TH, Lam KH, Miller MR, Zhang WS, Thomas GN, Adab P: Passive smoking exposure and risk of COPD among adults in China: the Guangzhou Biobank Cohort Study. Lancet 2007; 370:751-757.

36 Johannessen A, Omenaas ER, Bakke PS, Gulsvik A: Implications of reversibility testing on prevalence and risk factors for chronic obstructive pulmonary disease: a community study. Thorax 2005;60:842-847.

37 Pellegrino R, Viegi G, Brusasco V, Crapo RO, Burgos F, Casaburi R, Coates A, van der Grinten CP, Gustafsson P, Hankinson J, Jensen R, Johnson DC, MacIntyre N, McKay R, Miller MR, Navajas D, Pedersen OF, Wanger J: Interpretative strategies for lung function tests. Eur Respir J 2005;26:948-968.

38 Johannessen A, Lehmann S, Omenaas ER, Eide GE, Bakke PS, Gulsvik A: Post-bronchodilator spirometry reference values in adults and implications for disease management. Am J Respir Crit Care Med 2006;173: 1316-1325

39 Carre PC, Roche N, Neukirch F, Radeau T, Perez T, Terrioux P, Ostinelli J, Pouchain D, Huchon G: The effect of an information leaflet upon knowledge and awareness of COPD in potential sufferers. A randomized controlled study. Respiration 2008;76:53-60. 